Témoigner

Getuigen
Témoigner. Entre histoire et mémoire

Revue pluridisciplinaire de la Fondation Auschwitz

$118 \mid 2014$

Au nom des victimes. Dictature et terreur d'État en Argentine, Chili et Uruguay

\title{
Het verhaal van de Noche de los Lápices. De verdwenen schoolkinderen als 'onschuldige slachtoffers'
}

La Noche de los lápices et les victimes-innocentes. La construction de récits autour des lycéens disparus

The narratives construction in relation to secondary school pupils: The Noche de los lápices and the innocent victims

\section{Sandra Raggio}

Traducteur : Antonia García Castro

\section{OpenEdition}

\section{Journals}

Édition électronique

URL : http://journals.openedition.org/temoigner/1101

DOI : 10.4000/temoigner. 1101

ISSN : 2506-6390

Éditeur :

Éditions du Centre d'études et de documentation Mémoire d'Auschwitz, Éditions Kimé

Édition imprimée

Date de publication : 1 octobre 2014

Pagination : 98-105

ISBN : 978-2-84174-674-3

ISSN : 2031-4183

Référence électronique

Sandra Raggio, «Het verhaal van de Noche de los Lápices. De verdwenen schoolkinderen als 'onschuldige slachtoffers' », Témoigner. Entre histoire et mémoire [Online], 118 | 2014, Online op 01 octobre 2015, geraadpleegd op 23 octobre 2020. URL : http://journals.openedition.org/temoigner/ 1101 ; DOI : https://doi.org/10.4000/temoigner.1101 


\section{ARGENTINIË}

\section{Het verhaal van \\ de.Noche de los Lápices}

Deverdwenen schoolkinderen

als 'onschuldige slachtoffers'

$\rightarrow$ Sandra Raggio, de La Plata

(1) Voor meer informatie verwijs
ik naar Inés González Bombal, Nuar cas Más. El juicicio más alla de
Nus destrados' in Carlos Acuña ea. los estrados', in Carlos Acuña e.a.,
Juicio, castigos y memoria, Buenos
Aires: Nueva Visión. 1995: Luis Aires: Nueva Visión, 1995; Luis
Alberto Romero, Memorias de El Proceso', Lucha Armada 10, 2008,
4-10, Hugo Vezzetti, Pasado y
Presente Guerza dictaduray Presente. Guerra, dictadura y
sociedad en la Argentina, Bueno Aires: Siglo XXI, 2002. (2) Inés Gonzalez Bombal \&
Oscar Landi, 'Los derechos en Ia
cultura política', in Carlos Acuña e.a., op. cit.

(3) Claudia Feld maakt elders analyse van de verslaggeving lichamen, die zij als horrorshow' lichamen,

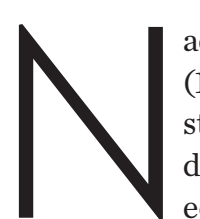

dat de Falklandoorlog het einde had ingeluid van de militaire dictatuur (1976-1983) en Argentinië geleidelijk evolueerde naar een democratie, roomden de berichten over de schending van mensenrechten onder

de junta binnen. De jonge democratie ontleende haar legitimiteit aan en radicalebreuk jothe dautoritaireverleden: aij was in principea wat de dictatuur niet was ${ }^{1}$ De controle-en censuurmechanismen die de militaire overheid had ingesteld waren niet meer zo strikt, en dat bracht volgens de terminologie van Landi en González Bombal ${ }^{2}$ een proces van 'her-informering' op gang. Al snel begonnen 'gruwelverhalen' over het verleden te circuleren, die een nieuw licht wierpen op de militaire periode en het middelpunt gingen vormen van het post-dictatoriale discours. De ontdekking van de lichamen van verdwenen personen in NN-graven was het symbolische begin van een nieuw tijdperk. De opgravingen brachten letterlijk de duistere geheimen van het verleden naar boven. ${ }^{3}$ Een van de belangrijkste taken van de democratie in wording lag dan ook in de reconstructie van de feitelijke waarheid van die gebeurtenissen.

Het dictatoriale regime had de meest evidente sporen van zijn misdaad uitgewist, namelijk de lichamen en de identiteit van de slachtoffers. Bovendien hadden de militairen de overlevenden monddood gemaakt en oefenden ze druk uit op personen die de stilte zouden kunnen doorbreken. In het democratische bestel herwonnen deze mensen hun rechtop spreken. Ook de achterdocht tegenover overlevenden die waren vrijgelaten en daarom verdacht werden van collaboratie, werd daadkrachtig de kop ingedrukt. Verhalen van slachtoffers werden nu gezien als een belangrijke bron van informatie, en vormden een machtig wapen in de strijd tegen de vergetelheid. Zowel in de privésfeer als in de publieke ruimte doken vreselijke verhalen op. Sommige zijn wijdverspreid geraakt en hebben sindsdien nooit aan kracht ingeboet. Andere zijn ondertussen vergeten, deden de ronde in beperkte kring of maakten enkel deel uit van de persoonlijke herinnering. We kunnen onmogelijk alles te weten komen over vande de misdaden

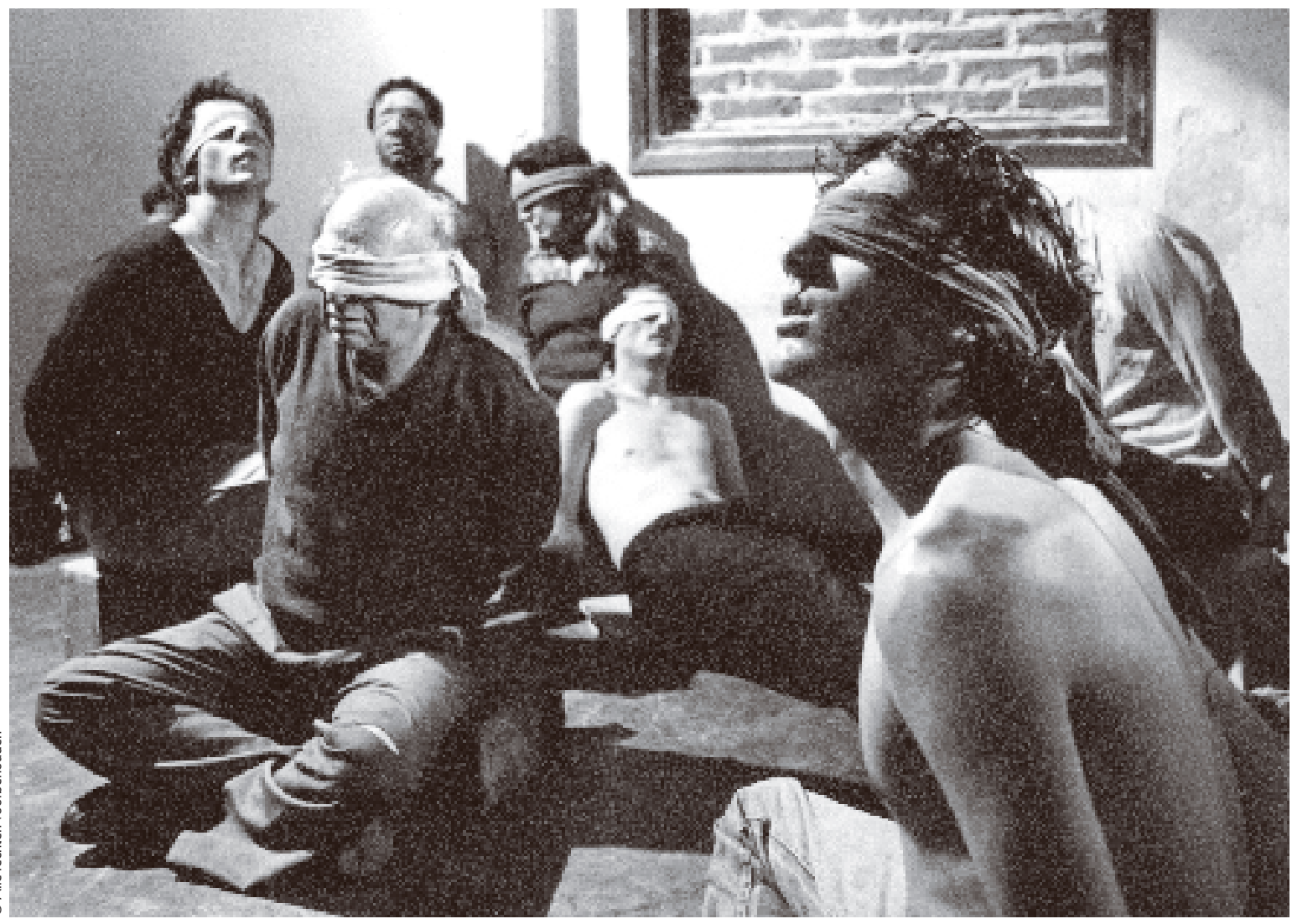

ze niet konden vertellen. Er zijn zoveel feiten waarover alleen daders de waarheid - Beeld uit de film La Noche de los Lápices van
Héctor Olivera (1986) kennen, omdat er geen sporen van terug te vinden zijn in getuigenissen of andere documenten.

Elk feit, hoe onbekend ook, vormt echter een onmisbaar puzzelstuk in het grote verhaal dat in de vroege jaren van de democratie tot stand kwam. Onvolledige of onjuiste versies, verkondigd door de militairen, werden finaal ontkracht. Zo was er de versie van de 'vuile oorlog', die de repressie inpaste in een 'antisubversieve oorlog', een soort van noodtoestand waarbij bepaalde activiteiten opeens als crimineel werden beschouwd. Dat argument werd van tafel geveegd door de Nationale commissie voor de verdwijning van personen (CONADEP, 1984). Uit de resultaten van haar onderzoek, die de commissie publiceerde in het rapport Nunca Más, bleek duidelijk hoe systematischen planmatio hetgeweld tijdens de dictatuur was seweest. Het rapport vol en het deblokkeerde het vc werd vanuit een nieuw perspectief bekeken, geïnterpreteerd en herdacht' ${ }^{4}$ Ook de veroordeling (4) Emilio Crenzel, Historia
politica del Nunca Más, Buenos
Aires: Siglo XX1, 2008, 103 
van de kopstukken van het dictatoriale regime in 1985 - tijdens het proces tegen de voormalige commandanten van de militaire junta - stond in scherp contrast met het verhaal van de 'vuile oorlog'. Tijdens dat proces werd immers juridisch bewij geleverd van het stelselmatige karakter van de repressie. Dankzij het onderzoek van de CONADEP en de gerechtelijke procedure kon de Argentijnse samenleving een 'onbetwistbare en onwrikbare waarheid' vastleggen over de gebeurtenissen en eindelijk het dictatoriale tijdperk achter zich laten. ${ }^{5}$

'We kunnen spreken van een crisis van het gezag', zo stelt Bazcko, 'wanneer het aantal concurrerende maatschappijbeelden toeneemt. Er ontstaan nieuwe invullingen van legitimiteit en nieuwe visies op de toekomst, die zich steeds meer opdringen en gehoor vinden bij brede lagen van de bevolking. ${ }^{6}$ In de vroege overgangsjaren was de herinnering aan de dictatuur nog levendig, maar koesterden vele burgers a democratische hoop. Het was de rol van de overheid om een nieuwe legitieme basis te vinden voor haar macht. Die legitimiteit zou stoelen op een democratisch wereldbeeld dat tot dan toe niet bestond, en dus moest worden uitgevonden. 'Op wat anders dan een illusie kon men de democratie bouwen?' vraagt Bazcko zich af. ${ }^{7}$ Het land stond voor een enorme uitdaging. De staat wenste de erfenis van de dictatuur niet door te trekken, maar werd tegelijkertijd onder druk gezet door bepaalde sectore wie de democratische idee misschien wel gevaarlijk waren, en herinneringen opriepen aan de revolutionair utopie en het geweld uit het verleden. De kunst bestond er dus in om afstand te nemen van het verleden: niet alleen van het dictatoriale regime, maar ook van de aanhoudende maatschappelijke en politieke conflicten die eraan voorafgingen.

Een van de bekendste verhalen over de dictatuur is ongetwijfeld de Noche $d e$ los Lápices (de Nacht van de potloden). In de nacht van 16 september 1976 werden zes adolescenten aangehouden en ontvoerd in La Plata, onder wie Pablo Díaz, die het voorval overleefde. De scholieren, zo klinkt het, hadden deelgenomen aan protestacties voor buspasjes.

Sinds de overgangsperiode doet het verhaal de ronde en vormt het een kritisch Simenter op de verschriklingenvand herdenkingsplechtigheden maar ook daarbuiten, werd de Noche de los Lápices opgerakeld om de 'geschiedenis' van het recente verleden te illustreren.

De Noche de los Lápices is niet zozeer een gebeurtenis of een opeenvolging van gebeurtenissen, maar veeleer een narratief schema waarin bepaalde episodes uitgekozen en met elkaar verweven werden om betekenis te geven aan het verleden Zo ontstond een logisch verband tussen een aantal min of meer willekeurige en losstaande feiten: een serie ontvoeringen binnen een korte tijdspanne, een groep slachtoffers die verwantschap vertoonden (leeftijd, school, woonplaats, achtergrond) en een motief. De 'gebeurtenis' is dan de 'Nacht van de potloden' gaan heten Die naam vat eigenlijk de hele geschiedenis samen. Eerst en vooral is de nacht een veelgebruikte metafoor voor de periode van de dictatuur, marhierverwijstde term cons eraan

\section{ONSCHULDIGE SLACHTOFFERS}

Bijna iedereen in Argentinie kent het verhaal dankzij Pablo Diaz, de 'enige overlevende' die getuigde tijdens het proces van de militaire junta. Er verschenen zelfs een boek en een film op basis van zijn getuigenis, die een enorm succes kenden: het boek werd meer dan tien keer herdrukt en de film wordt twintig jaar later nog steeds vertoond voor een ruim publiek. Men heeft er in Argentinië een gewoonte 列 hele land.

In de Noche des los Lápices worden andere verhalen over de dictatuur betwist namelijk de versie van de 'vuile oorlog' die de militairen verdedigen en de 'theorie van de twee duivels' die de Radicale Burgerunie na 1983 promootte in de regering Alfonsín-Martinez. Die twee versies bieden niet alleen verschillende ideologische en politieke perspectieven om het verleden te begrijpen, ze hebben ook een eigen juridisch en strafrechtelijk luik. In een 'vuile oorlog' dragen de onderdrukkers immers geen enkele verantwoordelijkheid: zij deden slechts hun werk en voerden onvermoeibaar strijd tegen 'subversieve elementen'. Die versie van de feiten werd dan ook verdedigd door de advocaten van de commandanten tijdens het proces van 1985. De theorie van de twee duivels legt dan weer de verantwoordelijkheid voor

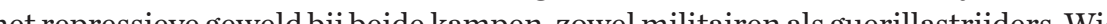
het represiens. Wie het verhaal vande Noche de feiten en dus strafrechtelik en politiek geheel waardeloos is. In wat voor oorlog valt men ongewapende adolescenten aan die 'gewoon een buspasje wilden'? Wie zijn de 'twee duivels' in dit verhaal?

De Noche de los Lápices is een mooi voorbeeld van een groot verhaal dat de 'mythe van de onschuld' en van het 'onschuldige slachtoffer' in stand houdt.' Dat gebeurt voornamelijk door de typering van de verdwenen personen. Zij zijn in het algemeen 'onschuldig' en dus ook 'niet schuldig aan subversie of terrorisme', nochtans naar alle waarschijnlijkheid de reden waarom ze zijn ontvoerd door het militaire regime. Het meest opmerkelijke an dit verhal is dat er amper gewas wordt gemakt van Het molitiont van het politicke nog hun lidmaatschap vangewapende revolutionaire organisaties. Voor de hyperslachtoffers ${ }^{10}$, zoals Inés González Bombal hen noemt, en vooral voor kinderen en adolescenten, is in dit soort verhalen een wezenlijke rol weggelegd. Hun lijdensweg is een aanklacht tegen het 'radicale kwaad' en stelt het gezag in vraag dat burgers terroriseert door gedwongen verdwijningen. ${ }^{11}$

Het fenomeen van 'hyperslachtoffer' is niet nieuw. Ook voor de democratische overgang, tijdens de dictatuur, stonden 'onschuldige slachtoffers' centraal in het mensenrechtendiscours. De verdwenen schoolkinderen duiken in 1980 op in het rapport van de CIDH (Interamerikaanse commissie voor mensenrechten binnen de Organisatie voor Amerikanse staten) en in andere docum tenorganisaties. tenorganisaties. De CONADEP spreekt erover, en ze zijn de hoofdpersonages uit
(8) Marcos Novaro \& Vicente Palermo, Historia Argentina 9. La
Dictadura militar 1976/1983. Del Golpe de Estado a la restauracion democrática, Buenos Aires:
Paidós, 2006. 487-488.

(9) De meeste verdwenen revolutionaire organisaties of hadden elders actie gevoerd. Dat rechtvaardigt in geen geval,
zoals de militairen beweerden, het geweld en de schending van mensenrechthen waarvan $z i j$
slachtoffer żin geworden

(10) Inés González Bombal, los estrados' op cicio más allá de (11) Dit verhaal ontstond tijdens
de processen. In de bewijsvoering werd meermaals verwezen naar de 'onschuldige slachtoffers', waren aan een misdaad. De term dook daarna op in andere
verhalen en werd het synowien van 'apolitieke personen'. Wie zich wel politiek engageerde was biggevolg verdacht. Vgl. Hugo
Vezzetti, Pasado y Presente. Guerra, Aictadura y sociedad
en Ia Argentina, Buenos Aires
Siglo $X X 1,2002,118$. 
jongeren, er is iets bijzonders mee. Het rapport Gevangen en verdwenen jongeren van het CELS (Centrum voor rechts- en maatschappijwetenschappen, een mensenrechtenorganisatie opgericht eind jaren zeventig) stelt klaar en duidelijk dat de scholieren het slachtoffer zijn geworden van een erg specifiek soort geweld:

De jongeren waren niet ondergedoken, verplaatsten zich op een normale manier en ze hadden normale relaties thuis, op het werk en op school. Het is daaromonmogelijk om he als een gevaar voor de samenleving te beschouwen.

als en yenar wijd Tijdens belastendzou hanne zijn. We vagno ons dan ook af welke logica hier werd gevolgd, en welke bedreiging juist werd gepareerd, toen het regime gewapende gevechtseenheden inzette tegen deze jongeren, hen geboeid en gemaskerd wegvoerde en in enkele gevallen zelfs meedogenloos aftroefde. Het aantal gemobiliseerde manschappen was bovendien volstrekt buiten proportie, gezien het feit dat de kans op verzet zo goed als onbestaande was. ${ }^{12}$

Het radicale slachtofferschap wordt gecultiveerd in dit nieuwe discours en roept in één krachtig beeld de gruwel van de staatsterreur op. De politieke achtergrond van de verdwenen personen en hun eventuele banden met revolutionaire organisatie worden volledig buiten beschouring Más, dat verscheen in de vroege jaren van de democratische overgang, reserveert een belangrijke plaat voor de figuur van de jongere. 'Adolescenten' delen door hun leeftijd bepaalde eigenschappen die van hen potentiële vijanden van de dictatuur maken. De groep van 'jongeren' uit de Noche de los Lápices wordt als volgt omschreven:

Ze zijn nog niet volwassen, maar het zijn ook geen kinderen meer. De bakens van hu leven worden geleidelijk uitgezet, maar hun toekomst ligt niet vast. Ze kennen de finesses niet van het politieke spel en zijn ook op cultureel vlak nog niet volleerd. Ze volgen hun gevoel, hun intuïtie. Ze weigeren zich neer te leggen bij de onvolmaakte samenleving die ze van hun voorouders hebben goërff. Sommigen onder hen zijn idealistischingesten

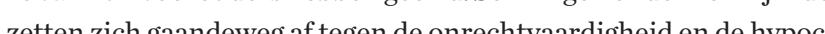
uit medeleven en uit medeleven en narviteit. Misschien is het omdat ze hun eigen lichaam zo ingrijpend voelen verander

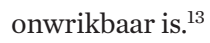

In de aantijgingen tegen het regime en de veroordeling van het geweld trad de figuur van de jongere als 'hyperslachtoffer' steeds vaker op de voorgrond. Het wa (12) CELS, Adolescentes Wij onderstrepen. (13) CONADEP, Nunca Más,
lnforme de la Comisión Nacional sobre la Desaparición de Persona een manier om zin en structuur te geven aan de gebeurtenissen, en het heikele pun van het politieke activisme te omzeilen. Nunca Más ligt in diezelfde lijn: de slachtoffers van de staatsterreur, zo benadrukt het rapport, waren voor het overgrote deel onschuldig, en dan meer bepaald 'niet schuldig aan terrorisme' 14 Het stilzwijgen over de politieke activiteiten van de slachtoffers is begrijpelijk, als men ziet hoe over de palieke a tiet hoe mensen por lich ontstaan. Wel integendeel, de bestaande verhalen bleven circuleren in de democratische overgangsjaren en gingen steeds zwaarder wegen op het herinneringswerk.

\section{PABLO DÍAZ: OVERLEVENDE, GETUIGE, SLACHTOFFER}

Het verhaal van de Noche de los Lápices was doorslaggevend om het tijdperk van de repressie te duiden en aanschouwelijk te maken. De kracht ervan kan nauwelijks onderschat worden en is toe te schrijven aande getuigenis van Díaz Al 'e lijks overlevende' van de ontvoerde scholieren werd hij al snel een publiek figuur. Zijn verhaal werd in boekvorm uitgebracht en zelfs verfilmd. In de getuigenis die hij aflegde tijdens het proces tegen de oud-commandanten van de junta, zien we hoe tijdens de reconstructie van de gebeurtenissen een narratief kader ontstaat dat bijzonder invloedrijk zal blijken.

Op 9 mei 1985 verscheen Díaz voor de rechtbank;'s anderendaags stonden foto's en flarden uit zijn getuigenis in alle kranten. ${ }^{15}$ Voor het eerst las een groot publiek het relaas van iemand die de 'nacht van de potloden' had overleefd. ${ }^{16}$ Het Diario del juicio (Dagboek van het proces) bevat de gestenografeerde versies van Díaz' drie verklaringen over de zaak Op de dag van zijn getuigenis zat María Seoane in de zaa luisteren, de journliste die later het bek zou schrijen Díaz antwoordde op de vragen van de rechters en begon toen zijn relaas ${ }^{17}$ Daarbij liet hij zijn eigen ontvoering, die nochtans pas op 21 september plaatsvond, deel uitmaken van de kroniek van de beruchte zestiende september. De reden voor de militaire interventie, zo stelde hij, was zijn deelname aan de protestactie rond de buspasjes.

Dr. D’Alessio: Vergeef me, voor ik de draad kwijtraak, wat is nu weer uw relatie met de andere jongeren die waren aangehouden?

Pablo Díaz: Ik heb hen later gezien in de concentratiekampen..

Dr. D’Alessio: Nee, ik bedoel: hoe kenden jullie mekaar?

Pablo Díaz: Dat was voor de buspassen voor school, dat was een van onze eisen, van de Coordinadora de Estudiantes Secundarios van La Plata. We waren met een hele hoop scholieren tussen veertien en achttien jaar, en we waren samen naar het Ministerie voor Openbare werken getrokken dat zich bezighield met vervoerskwesties, daar hebben we elkaar ontmoet. We hebben elkaar gezien maar we kenden elkaar niet, het is pas later, toen ik hen tegenkwam in de verschillende kampen waar ik ben verbleven, en na de ondervragingen, dat ik het grote geheel zag. ${ }^{18}$

Díaz vertelt hier niet alleen wat hij heeft 'beleefd', maar probeert te begrijpen wat hij heeft meegemaakt door er een verhaal rond te breien. Het verhaal van iemands leven is niet hetzelfde als dat leven zelf: ook als iemand zijn eigen ervaringen vertelt, is de hoofdpersoon in het verhal steeds een ander, en valt die nooit volledig samen met de verteller. Meer nog men issen, die het eigen verhaal bevestigen, aanvullen of misschien net tegenspreken. Soms lijkt het nodig om aanpassingen te maken en de gebeurtenissen op een andere manier te

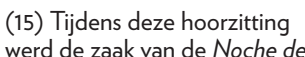
los Lápices behandeld. Andere getuigigen werden gehoord, maar
geen van hen was van invloed op de verklaringen van Díaz.

(16) Hij is zich bewust van de blijkt uit een reportage die in 1988 in het tijdschritt Nueva Proyeccio verscheen: Achterat, in 1984, school, heb ik moeten getuigen het proces tegen de junta.l lk werd school.' (Centro de Estudiantes del Colegio Nacional de la Plata, Plata, 1988, 33).

(17) Diario del juicici, 3 ,
11 juni 1985, 62-66.

(18) bid., 62, de auteur 
reconstrueren. Wanneer we de verklaringen van Díaz bij de CONADEP vergelijken met die tijdens het proces, stellen we vast dat zijn getuigenis voor de rechtbank 'vollediger' was. Dat komt omdat Díaz zich toen al kon beroepen op andere verklaringen. Hij incorporeerde nieuwe elementen in zijn relaas en wist zo de feiten uitdrukkelijker te interpreteren: een onbekende stem kreeg plots een naam en een gezicht, een anekdote werd verbonden aan een precieze datum. In die zin is het verhaal van Díaz (19) Wanneer we zijn getuigen
omschriven als fictio, bedoelen we niet dat Díaz liegt', de waarheid niet vertelt' of een
'valse' verklaring aflegt. De ter is ontleend aan Clifford Geertz,
'Thick Description: Toward an Interpretative Theory of Culture, Cultures, New York: Basic Bools

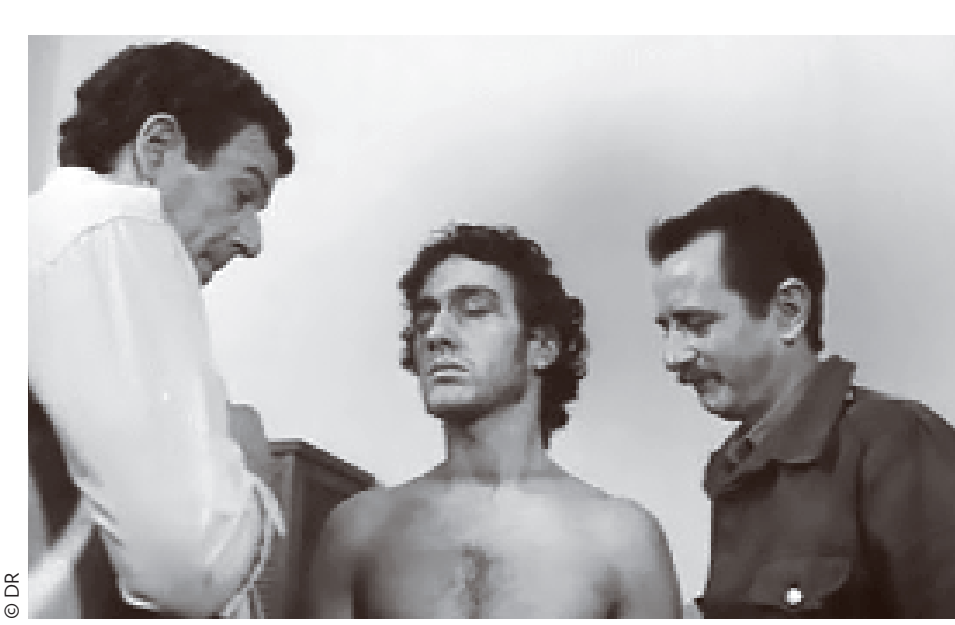
op zon ingrijpende manier 'bewerkt' D'́az' alloreerste getuigenis is bijvorbeld waarin die tot stand gekomen is

In zijn 'bewerkte' getuigenis zal Díaz een verklaring zoeken voor de gebeurtenissen. De 'zaak' die in de rechtbank wordt behandeld, valt volgens hem terug te brengen tot de strijd om de buspasjes. Daar begon het allemaal mee. Het verband dat de getuige legt tussen de studentenprotesten en zijn eigen ontvoering is nochtans niet vanzelfsprekend, maar geeft precies weer hoe hij vat tracht te krijgen op de gebeurtenissen. Díaz ziet hij dat hij niet alleen was: hij kan zich identificeren met lotgenoten en daardoor een gedetailleerder verhaal brengen over zijn eigen ervaring. Door de gelijkenissen die hij opmerkt in de twee zaken, associeert hij zijn eigen ontevende, degene die moet speken is is gen op 16 septenber. Zj' belichamen 'de ander', waarnaar Diaz steeds verwijst om zijn eigen verhal op te bouwen. Wanneer hijeen verklaring aflegt in de rechtbank, speelt hij in feite drie rollen: in de eerste plaats die van 'overlevende', maar ook die van 'slachtoffer' en 'getuige'. Zijn taak van overlevende bestaat erin de afwezigen weer aanwezig te maken. Daarenboven is hij een bijzonder soort overlevende: hij is 'uniek', niet omdat hij de 'enige' getuige is - andere overlevenden konden immers ook bevestigen dat zij 'erbij waren' en getuigden tijdens het proces - maar door de manier waarop hij zijn verhaal construeert. Dat volgt duidelijk het algemeen gangbare schema dat we ook teruguinden in Nunca Más. Diaz werpt zich op als de "enige minderjarige schoolgaande jongere die streed voor de buspasjes en die getuige was van de feiten'.

Omdat de getuige 'erbij was', is zijn verhaal bijzonder geloofwaardig en zou men haast vergeten dat het hier gaat om een fictio. Diáz doet zijn relaas voor de rechtbank onder invloed van het officiële discours van de CONADEP, datop zich al een 'bewerking' van de geschiedenis is een be Hij beschrijft de feiten op exact dezelfde rapport Nunca Más. De getuigenis is opgebouwd volgens de klassieke interpretatieschema's van de overgangsjaren, maar legt in een persoonlijk verhaal wel een bijzonder traumatische ervaring bloot. Dat geeft de verklaring van Díaz een buitengewone kracht, zeker wanneer die later hernomen wordt in een juridische context. Toch was het verhaal van Díaz meer dan een individuele getuigenis voor de rechtbank. De jongeman richtte zich tot de hele Argentijnse samenleving, waar op dat moment een intens debat woedde over het dictatoriale verleden. Ondanks verschillende pogingen uit de politieke sector om de discussie open te trekken, blifft het verhal pogingen van de dicta de polite en 'slachtofs. onschuld' vormt een essentieel frame waarbinnen de Argentijnen hun gewelddadige verleden begrijpen. De rol van Díaz in dit proces, als iconisch slachtoffer van de staatsterreur, kan men moeilijk onderschatten.

$$
* *
$$

In de loop der jaren ontstonden telkens nieuwe, en sterk verschillende, verhalen over deverd wijningen ende dictatuur Datvan de Noche delos Lápices houdtechter over de al enkele tientallen jaren stat er dus toch en zekereconting dictatorialeverleden verwertenheringert. Misschien valt datteverklaren door de aanwezigheid van oude betekeniskaders die mensen onbewust decennialang hebben doorgeven, en die hun denken tot op vandaag beïnvloeden. Actuele gebeurtenissen worden dan telkens in dezelfde gestandaardiseerde en universele schema's gegoten om zin en betekenis te geven aan de ervaring, zonder daarbij rekening te houden met de historische omstandigheden. In het licht van die vaststellingen lijkt het irrelevant om herinneringsmechanismen uitsluitend te willen verklaren op basis van de politieke context waarbinnen verhalen over de staatsterreur zijn ontstaan. Het is niet onwarschijnlijk dat we via een analyse van stereotiepe narratieve codes is niet onwark zichtbaar zouden zijn. We moeten onderzoeken hoe de samenleving haar verleden construeert, zonder witsluitend te focussen op de 'hennneringsondernemers ${ }^{20}$, mensenrechtenorganisaties, overlevenden of officiēle instellingen die het herinneringsbeleid mee bepalen. Integendeel, het loont de moeite om andere, 'secundaire' actoren voor het voetlicht te brengen, en te kijken hoe de mensen aan de kant van de 'receptie' soms om een heel andere vorm en betekenis aan het verleden geven.

.

